\title{
Importancia alimenticia del cultivo del frijol negro en Nicaragua
}

Norland J. Quezada Palacios

Docente investigador

Instituto de Investigaciones Económicas y Sociales (INIES-UNAN)

norland_quezada_pa@yahoo.com

Fecha de recibido: 6 abril de 2015

Fecha de aprobado: 18 de septiembre de 2015

\begin{abstract}
RESUMEN
Importancia Alimenticia del Cultivo del Frijol Negro en Nicaragua. El objetivo del presente trabajo es dar a conocer la importancia nutritiva que tiene este rubro que es tan importante en la dieta nicaragüense bajo el proceso fitomejoramiento participativo que involucra una participación activa de los agricultores en el país. La implementación de este rubro en el país ayuda a obtener altos rendimientos y resistencia múltiple a enfermedades y es adaptable ante la variabilidad climática y cambio climático. El cultivo del frijol posee una extraordinaria importancia para la alimentación humana, pues además de constituir una fuente esencial de proteína, forma parte de los hábitos alimentarios de la población nicaragüense. Por lo tanto, en Nicaragua las condiciones edafoclimáticas son favorables para su cultivo, por lo que se produce en la mayor parte del territorio nacional. El objetivo de este documento es dar a conocer el comportamiento productivo de nuevas líneas de frijol negro en condiciones adaptables climáticamente en el país. La implementación de este rubro en la dieta nicaragüense ayudaría a reducir enfermedades tales como: diabetes tipo II o enfermedades cardiovasculares. Con este trabajo se pretende dar un giro transversal en la importancia del frijol negro (Phaseolus vulgaris) en la dieta habitual de Nicaragua.
\end{abstract}

\begin{abstract}
Growing Importance of Food Black Bean in Nicaragua. The aim of this paper is to present the nutritional importance of this area that is so important in the Nicaraguan diet low PPB process that involves active participation of farmers in the country. The implementation of this sector in the country helps to obtain high yields and resistance to multiple diseases and is adaptable to climate variability and climate change. The bean crop has an extraordinary importance for human consumption, as well as being a key source of protein, it is part of the eating habits of the Nicaraguan population. Therefore, in Nicaragua the soil and climatic conditions are favorable for cultivation, so it occurs in most parts of the country. The purpose of this paper is to present the productive performance of new lines of black beans in climatically suitable conditions in the country. The implementation of this item in the Nicaraguan diet help reduce diseases such as type II diabetes or cardiovascular disease. This work is intended to provide a transverse spin on the importance of black beans (Phaseolus vulgaris) in the diet of Nicaragua.
\end{abstract}

Palabras Claves: Phaseolus vulgaris, L., Proteínas, Fitomejoramiento Participativo (FP), Cultivares, Estado Nutricional. 


\section{INTRODUCCIÓN}

La creciente necesidad de producir alimentos a nivel mundial, nos impulsa a ser eficientes en la generación de nuevas y mejores alternativas tecnológicas de producción de frijol, para ponerlas a disposición de los grandes, pequeños y medianos productores de este rubro a nivel nacional. Satisfacer la creciente demanda alimentaria de la especie humana es un tema de extraordinaria importancia y vigencia en todos los tiempos. Por ello, en todo el mundo, numerosos investigadores laboran incesantemente en la búsqueda de soluciones sostenibles.

El rubro de frijol es importantísimo en la dieta diaria de nuestra gente, superado en consumo solamente por el maíz. Representa un eslabón importante al momento de hablar de seguridad alimentaria en la región. En Nicaragua se siembran alrededor de 653,750 miles de manzanas anual con un rendimiento de $13.33 \mathrm{QQ} / \mathrm{Mz}$, lo que ha permitido ser autosuficiente en los últimos años, a excepción del resto de rubros que conforman la canasta básica familiar.

Es indudable que la adopción y utilización de muchas de esta variedad del frijol negro va contribuir significativamente con la seguridad alimentaria y en la mejora de las economías de las familias nicaragüenses. Sin embargo, en algunas áreas no se han obtenido los avances esperados lo que ha limitado la solución a problemas que ha sido afectada y ocurren con frecuencia a nivel de finca, como son la fertilidad del suelo, las plagas, las enfermedades, problemas varietales, condiciones climáticas adversas y la sequía. Asimismo, nuevos retos de índole agronómico, ecológico y socioeconómico requieren especial atención y soluciones a corto y mediano plazo, para que nuestros productores de frijol, en su mayoría de pequeña escala, lo puedan seguir cultivando, consumiendo, y generando un ingreso justo dentro de un marco sostenible y digno.

Bajo este contexto, se incluyen a los pequeños productores de cultivos básicos, que no poseen los recursos para modificar su ambiente productivo para poder obtener las respuestas en rendimiento de variedades mejoradas de mayor potencial. Sin embargo, en el caso de frijol negro en Centro América, las variedades mejoradas generadas de manera convencional han sido valiosas en reducir la diseminación de enfermedades que hubieran causado una reducción significativa del rendimiento, pe. el mosaico dorado amarillo. El fitomejoramiento participativo (FP), que involucra una participación activa de los agricultores en el desarrollo de variedades con adaptación específica, se presenta como una alternativa para incrementar el acceso y la adopción de variedades mejoradas para pequeños productores con limitado acceso a las tecnologías y/o bajo uso de insumos. En Centro América, ya existen algunas iniciativas de FP en los cultivos de frijol y 
maíz; a raíz de estas iniciativas, el interés y las expectativas de los agricultores, organizaciones y donantes han crecido recientemente.

Muchos son los cultivos que se emplean en la alimentación del hombre, y en este contexto, todos revisten vital importancia, pues en su conjunto se logran todos los elementos necesarios para su debida nutrición. Dentro de los que se caracterizan por aportar gran cantidad de proteínas y fibra. No contiene colesterol y son ricos en vitaminas B, hierro, calcio, potasio y fósforo, se encuentra el frijol negro. El frijol común (Phaseolus vulgaris, L.) constituye la leguminosa que ha sido objeto de más estudios en América Latina, por ser la fuente principal de proteína, así como por formar parte importante de los hábitos alimentarios de la población (Conrado, 2006).

El objetivo de este documento es diseminar información sobre las variedades mejoradas de frijol negro en los últimos años en Nicaragua. Con el fin de orientar las decisiones de los participantes de la cadena de valor de este rubro en la región.

\section{DESARROLLO}

\section{Consideraciones para la aplicación del FP en el mejoramiento del frijol negro}

Los caracteres cualitativos que se expresan fenotípicamente en el campo, pueden ser evaluados visualmente mediante escalas sencillas manejadas por los agricultores. Los caracteres cuantitativos como rendimiento, de baja heredabilidad y aquellos altamente influenciados por el ambiente, son más difíciles de evaluar con los criterios que emplean los agricultores. Como se sugiere para el mejoramiento del frijol negro, estas características cuantitativas deberán ser evaluadas en generaciones avanzadas y en lo posible con el uso de repeticiones. Las dificultades en transmitir estos conceptos de herencia cuantitativa de manera sencilla representan el reto más significativo en el desarrollo de una metodología de FO para una audiencia sin estos conocimientos básicos. Sin embargo, en la evaluación "en verde" (etapa de llenado de grano) que los agricultores hacen tanto en poblaciones segregantes como en líneas avanzadas, se emplea como un criterio importante la carga (vigor reproductivo), que es una medida indirecta de rendimiento; este mismo criterio es utilizado por los fitomejoradores en las evaluaciones de valor agronómico en esta etapa. 


\section{Metodología del fitomejoramiento participativo}

La aplicación de metodologías de fitomejoramiento participativo (FP) se presenta como una alternativa para facilitar el acceso de los agricultores a materiales mejorados con base genética más amplia, en los que puedan aplicar procesos de selección y validación que les permita desarrollar cultivares más productivos y estables, adaptados a sus condiciones agroecológicas y sistemas de producción, y de mayor aceptación culinaria y comercial. En este sentido, se considera al FP como el proceso en el que fitomejoradores y agricultores seleccionan cultivares a partir de poblaciones segregantes bajo un ambiente meta específico (Witcombe y Joshi 1996). Para algunos investigadores, el FP es la alternativa que se debe aplicar cuando las posibilidades de selección se han agotado, o han fallado en identificar cultivares deseables, o cuando los agricultores identifican problemas en los cultivares existentes.

Por otro lado, el FP es una alternativa para el mejoramiento de cultivos que crecen en condiciones desfavorables, regiones alejadas o áreas muy pequeñas, generalmente menos atendidas por los programas de mejoramiento tradicionales. Adicionalmente, el FP permite la selección de poblaciones segregantes en generaciones tempranas en el ambiente meta evitando la eliminación de líneas útiles que pueden ser descartadas por su relativo pobre comportamiento en condiciones más favorables, p.e. estaciones experimentales (Ceccarelli et al. 1996).

\section{Los recursos humanos en los enfoques de FP.}

Aunque algunos estudios etnobiológicos recientes han revelado que en muchos casos, los conocimientos locales de los agricultores eran equivalente o superior, y en muchos casos complementarios a los de los científicos (De Boef et al. 1995), será necesario en la mayoría de los casos contar con grupos de agricultores con cierto grado de experiencia previa en experimentación. Según esto, la necesidad de lograr que los agricultores adquieran los conocimientos y destrezas prácticas para conducir actividades eficientes de FP debe ser contemplada al implementarse esta metodología.

El FP es fundamentalmente una actividad colaborativa entre agricultores y fitomejoradores: a nivel de los agricultores se requiere la organización adecuada para lograr que se compartan las responsabilidades entre miembros de la comunidad. Hay que considerar que en un momento dado se podrán tener simultáneamente poblaciones segregantes bajo selección, ensayos de líneas avanzadas, parcelas de validación y producción artesanal de semilla. En las actividades de FP en Nicaragua, se colabora con agricultores organizados y el Instituto Nicaragüense de Tecnología Agropecuaria (INTA), 
los cuales poseen los mecanismos para compartir responsabilidades en la comunidad. Este mismo tipo de organización facilita la difusión de los avances logrados en el FP en cada etapa.

La participación de los miembros de la comunidad de género y edad diversa garantiza mayor eficiencia y participación en las actividades de FP, la responsabilidad compartida y la adopción de las variedades mejoradas. Las habilidades de las mujeres complementa a la de los hombres, y la participación de los jóvenes permite la sostenibilidad en el tiempo al preparar recursos humanos para el futuro. La comunidad representada por los grupos involucrados en actividades participativas como el FO, lograrán avances significativos en el desarrollo y adquisición de facultades para asumir responsabilidades y poder tomar decisiones basadas en los intereses de la mayoría.

\section{CONCLUSIONES}

Un incremento en la participación de los agricultores a través del FP ayudaría a aumentar los niveles de adopción de las variedades mejoradas y a reducir el costo sobre todo en la metodología recomendada para futuras validaciones. Por otro lado, se obtendría un mejor aprovechamiento del germoplasma con adaptación específica. Del mismo modo, se tendría acceso a agro ecosistemas bien identificados para pruebas de selección específica. Asimismo, al contar con colaboradores de muchas zonas de producción con experiencia en el manejo de viveros y ensayos, se facilitaría la identificación de germoplasma con amplia adaptación. Los agricultores participarían en la conservación in situ de los recursos genéticos al tener mayor conocimiento y usar más eficientemente sus variedades criollas.

Las experiencias en FP son todavía preliminares. La diseminación de su aplicación extensiva requiere del desarrollo de una metodología simplificada acompañada de la capacitación de técnicos y agricultores líderes. Sin embargo, se están buscando los recursos necesarios para expandir estas experiencias iniciales en Centro América y tratar de involucrar a programas nacionales y organizaciones de desarrollo.

El FP es un enfoque que permite mayor participación a los agricultores en el desarrollo de tecnologías útiles para sus comunidades. Se viene presentando como la alternativa para corregir las limitaciones en la adopción de variedades mejoradas generadas por los programas tradicionales. Diversas organizaciones y donantes han puesto mucho interés en estas alternativas y es posible que a corto plazo sea un requisito para lograr el apoyo financiero que los programas de la región centroamericana están viendo cada vez más escasos. 


\section{REFERENCIAS}

(FAO), O. d. (2007). Rendimientos de los Precios Centroamericanos de Frijoles Rojo y Negro. Rendimientos de los Precios Centroamericanos de Frijoles Rojo y Negro, 30.

(Upanic), U. d. (2007). Rendimientos Agrìcolas. Rendimientos Agrìcolas. P.20.

De Boef, W. B., y Haverkort, Y. B. (1995). El papel del agricultor en el desarrollo y conservación y diversidad de cultivos. Agronomía Mesoamericana, P.27. 